SLAC TN-06-031-Rev

September, 2006

\title{
SEY and Surface Analysis Measurements on FNAL Main Injector Ring S/S Beam Chamber Material
}

\author{
Robert E. Kirby \\ Surface and Materials Science Dept. \\ Stanford Linear Accelerator Center \\ 2575 Sand Hill Road \\ Menlo Park, CA 94025
}

Work supported by Department of Energy contract DE-AC02-76SF00515 


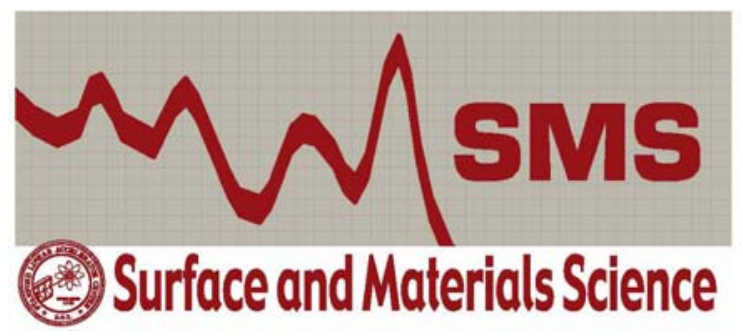

\section{Material}

Material was provided by Dr. Weiren Chou, FNAL. Both mildly-activated used, and new sections of stainless steel (type 316L) beam chamber were measured. Centimeter-sized coupons were cleanly dry-cut from the large flat surface (called "flat side" in the plots) and from the ID end (inside diameter of the ring, in the case of the used material) and narrow end (in the case of the new material). The unused material was ultra-soniced in acetone (to remove storage residue), then rinsed with ethanol and blown dry with filtered $\mathrm{N}_{2}$-gas, to simulate new chamber installation final rinse. Used material was installed, as cut.

\section{Surface Chemistry}

Surface chemistry was measured using $x$-ray photoelectron spectroscopy (sometimes called "ESCA"). With this technique, soft x-rays (1486 eV) illuminate the sample, penetrating into the surface ten microns. Photoelectrons are generated from energy levels of the constituent compounds/elements present. Those electrons, within $5 \mathrm{~nm}$ or so of the surface, escape without energy loss and preserve valence information about the atomic levels from which they were generated. An electron energy analyzer, of good energy resolution, measures the photoelectron energy, thereby yielding both valence (chemical) information and relative atomic abundances in the top $5 \mathrm{~nm}$ of surface. Using appropriate sensitivity factors, these intensities are coverted to a semi-quantitative (surface atom \%) concentration in the analyzed layer. As a benchmark, the limit for carbon contamination on vacuum components for UHV use at SLAC is 50 at $\%$. That corresponds to about 8-10 monolayers of elemental carbon. XPS does not detect hydrogen because it has no electrons after bonding. Generally, hydrides do not show evidence of "chemical shift" of the binding energy of the metal lines. 


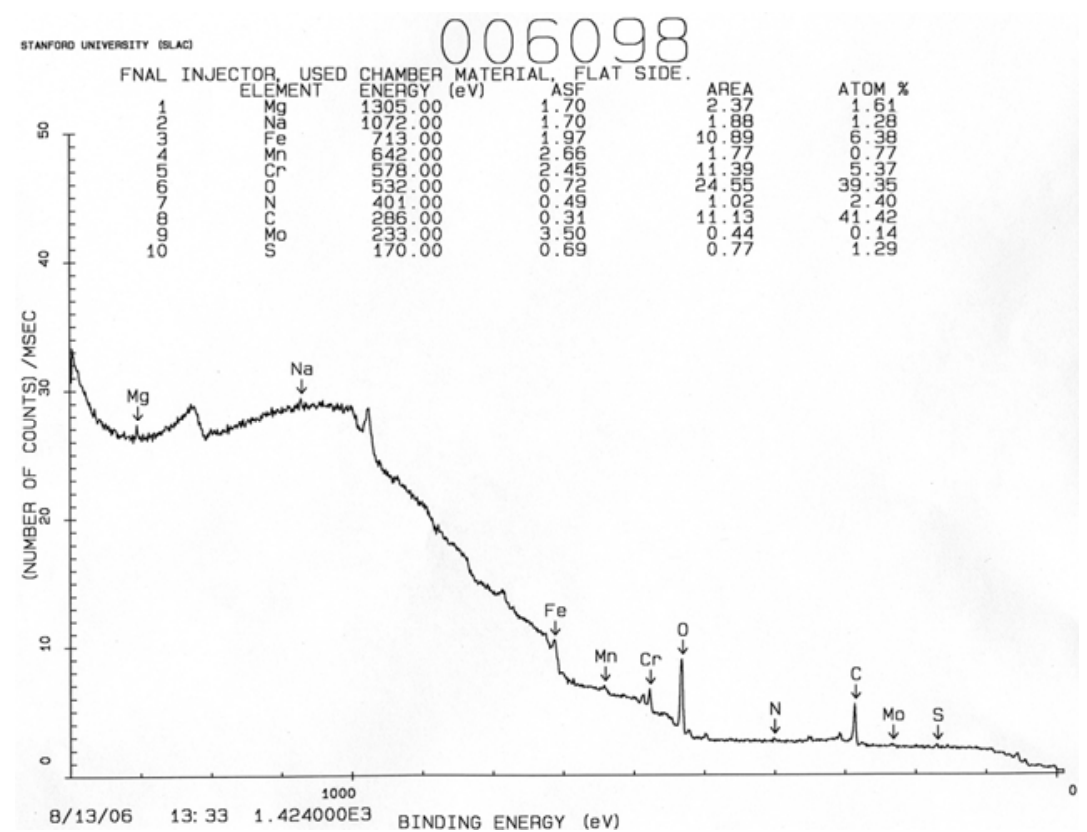

Figure 1. XPS spectrum of used S/S chamber material, flat side.

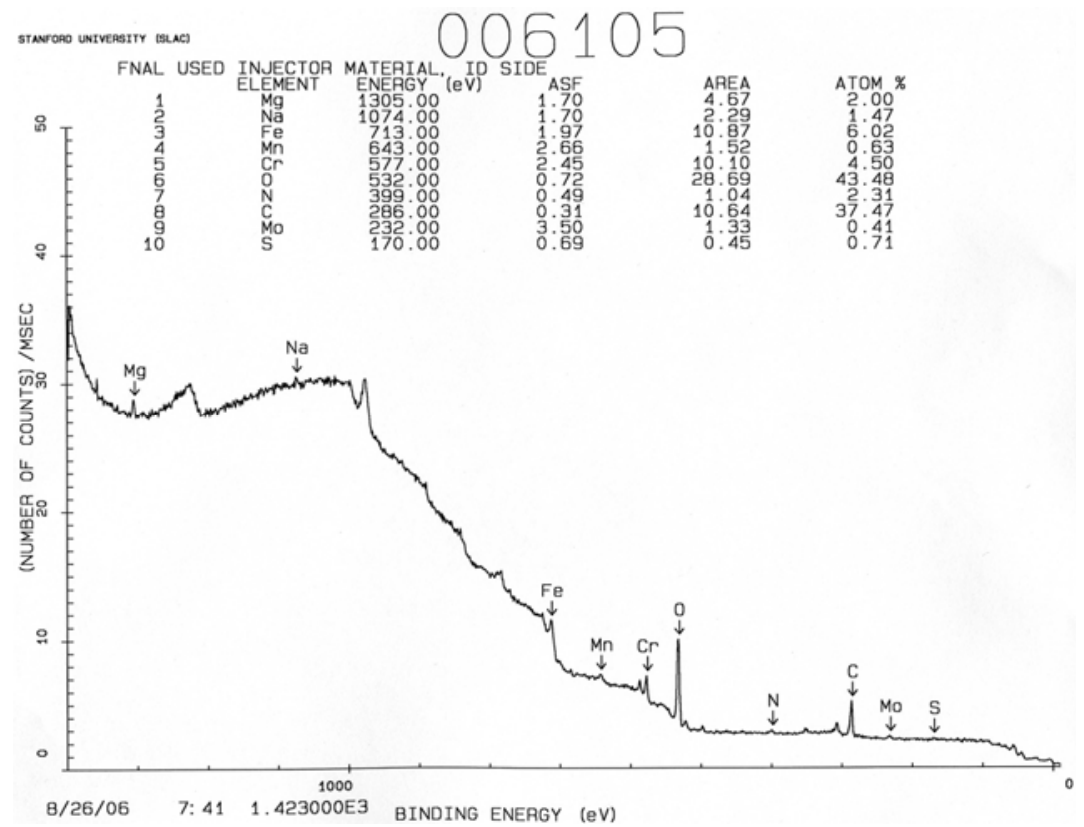

Figure 2. XPS spectrum of used S/S chamber material, inside-diameter (ID) side. 


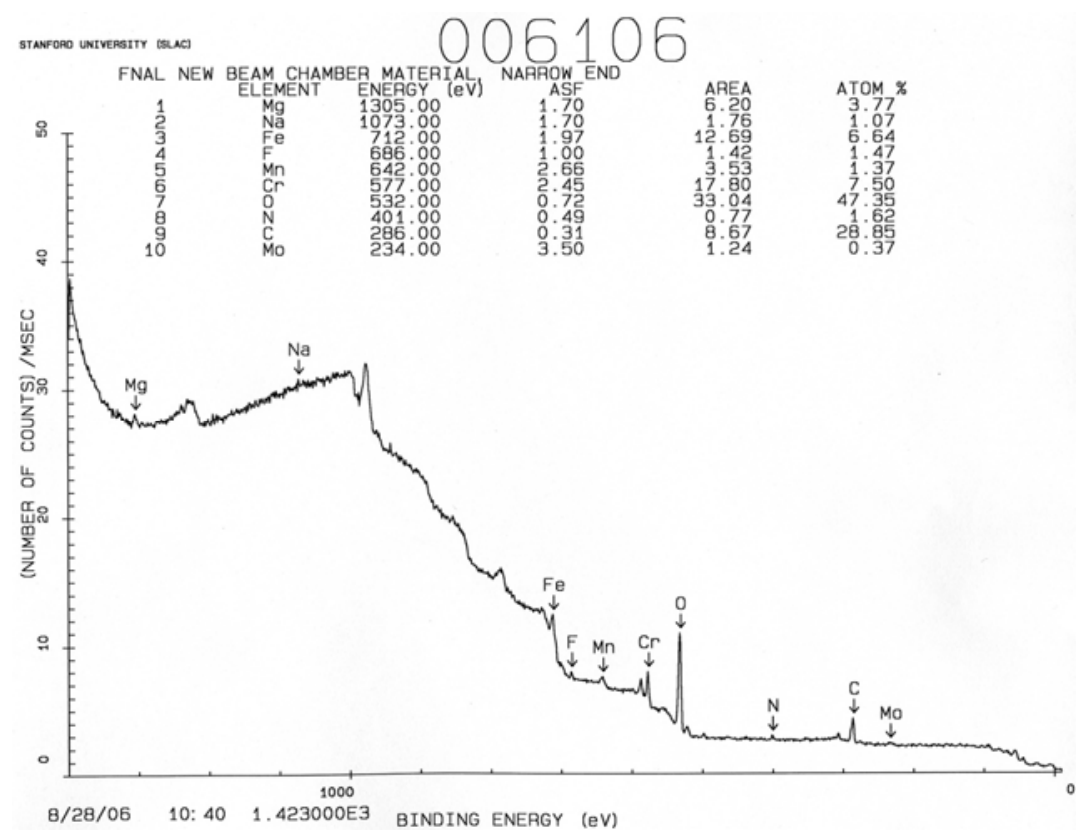

Figure 3. XPS spectrum of new S/S chamber material, narrow side.

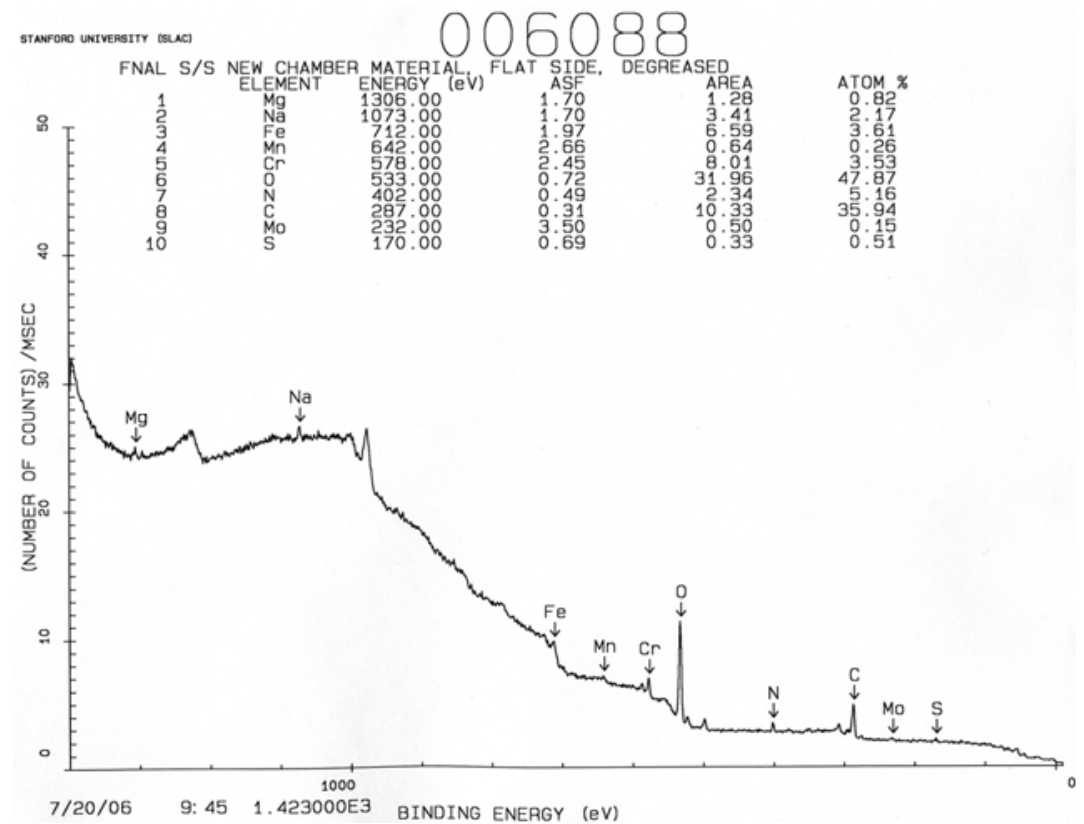

Figure 4. XPS spectrum of new S/S chamber material, flat side. 


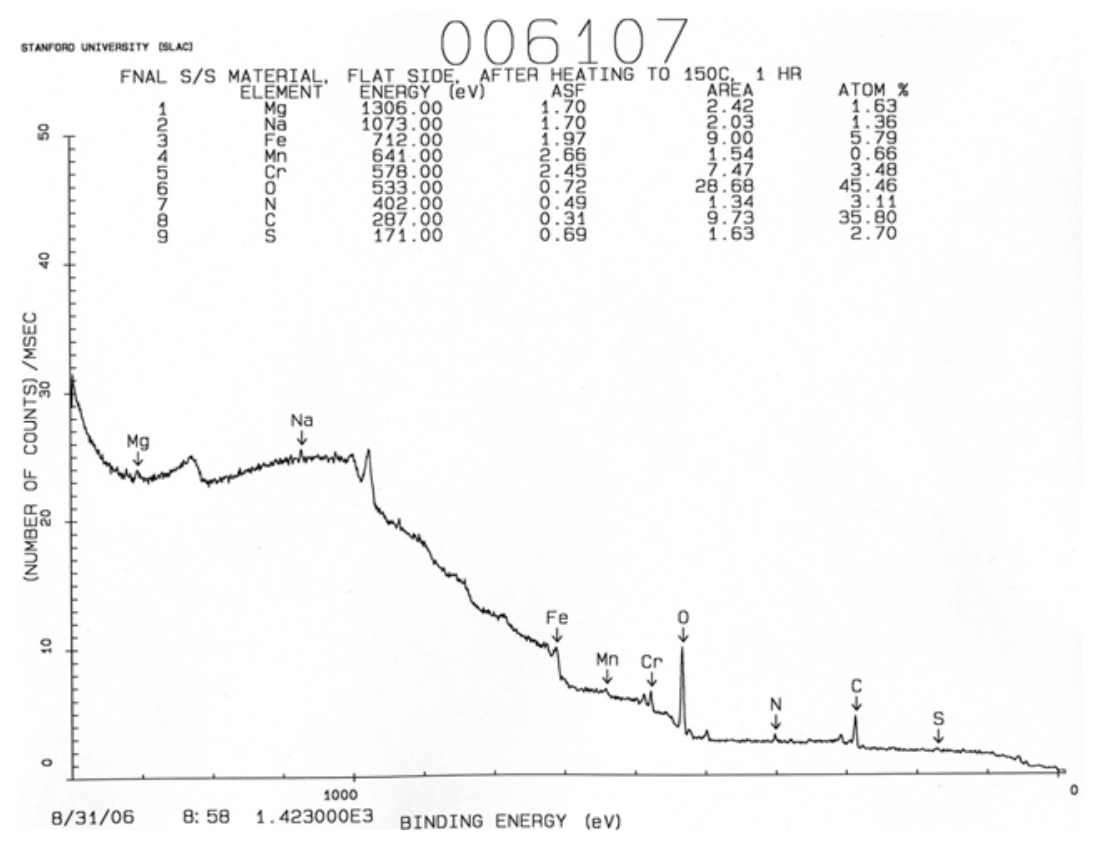

Figure 5. XPS spectrum of new S/S chamber material, flat side, after heating to $150^{\circ} \mathrm{C}$ for $1 \mathrm{hr}$ and cooling back to RT before measurement.

\section{Secondary Electron Yield}

Measurement of the yield was done prior to all XPS measurement, because the yield is very sensitive to gas coverage, particularly to carbon (lowers yield) and hydrocarbons and water (both raise yield). Heating the coupons usually lowers yield, by desorbing hydrocarbons and water. Below is the electronic schematic for our SEY measuring system. All yields were measured at room temperature.

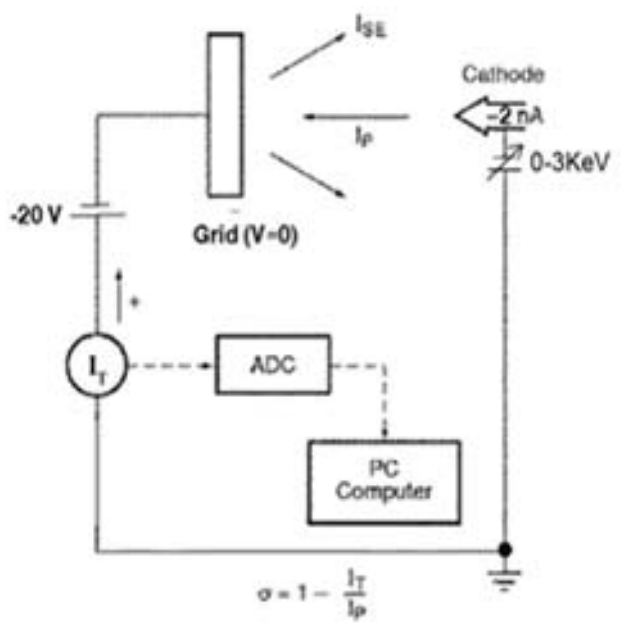

Figure 6. Electronic schematic for SEY measurement. The $-20 \mathrm{~V}$ retard on the sample prevents most secondaries electrons generated on the system walls from reaching the sample. 
Consistency checks were done on sputter-cleaned carbon and gold. The yield at the very lowest primary energies, say $<50 \mathrm{eV}$, is in error because the sample current measuring method does not include elastically-scattered primary electrons. At higher energies $(>50 \mathrm{eV})$, the error is small (a few percent, depending on atomic number). All measurements were done at normal incidence.

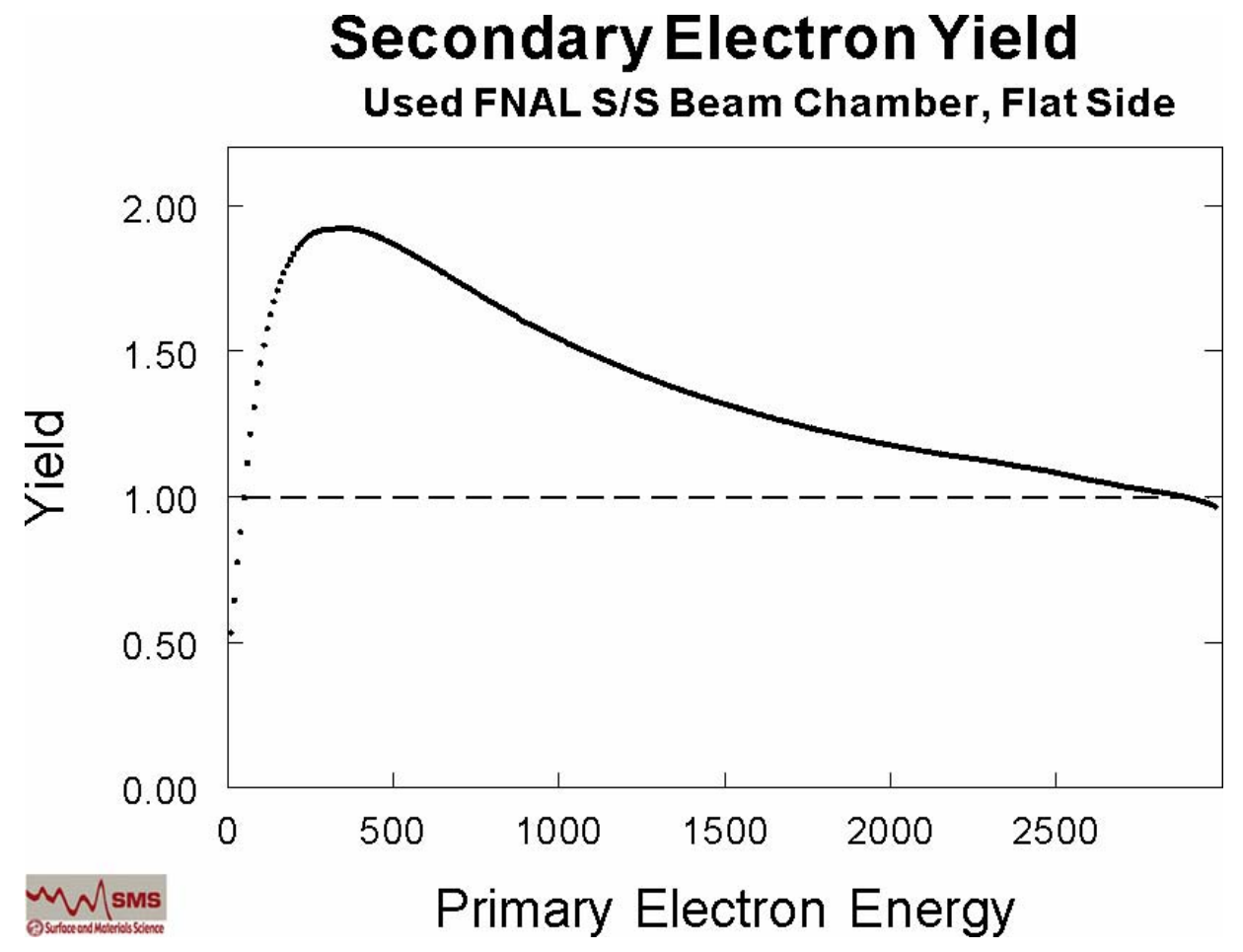

Figure 7. SEY of used S/S chamber material, flat side. 


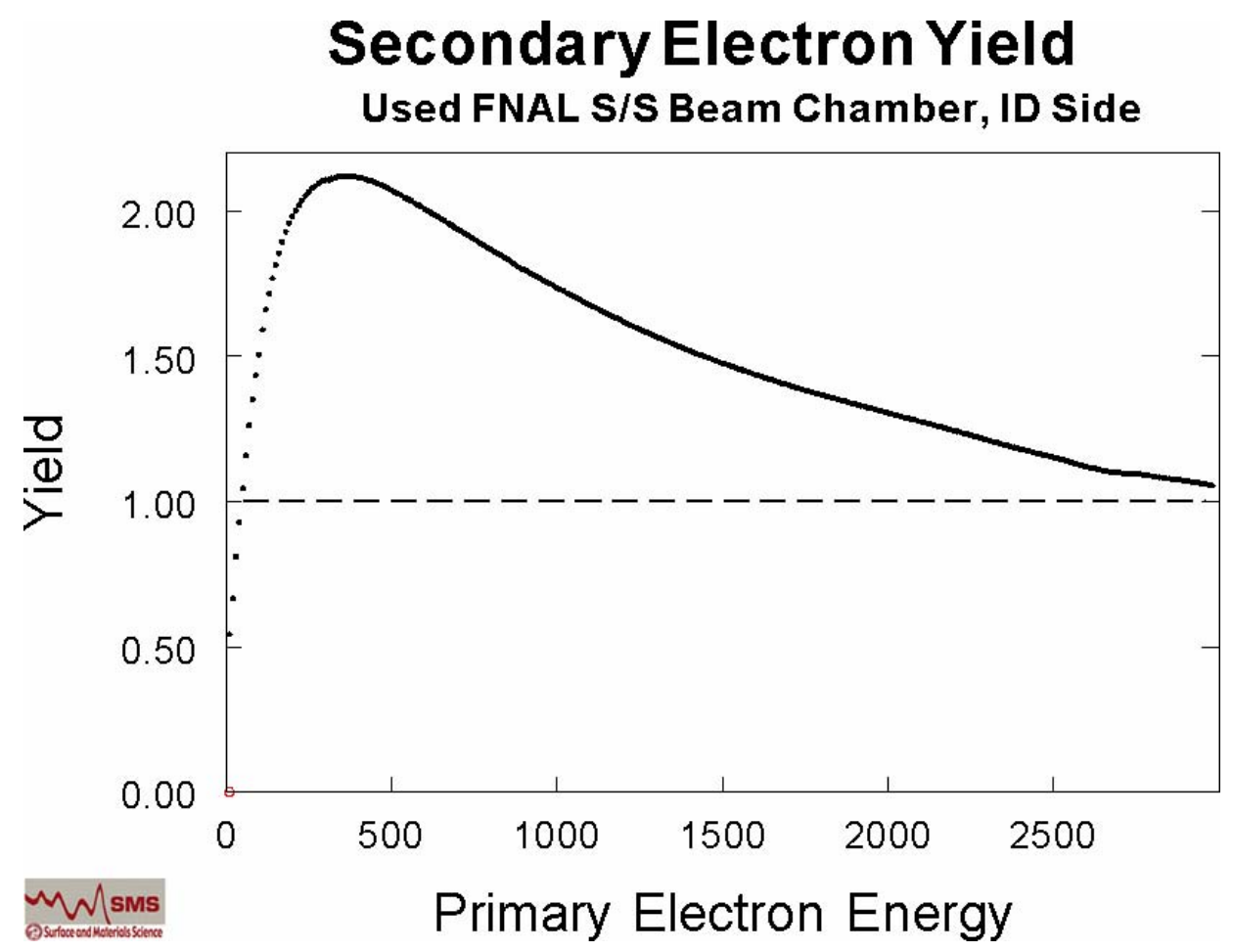

Figure 8. SEY of used S/S chamber material, ID side.

\section{Secondary Electron Yield}

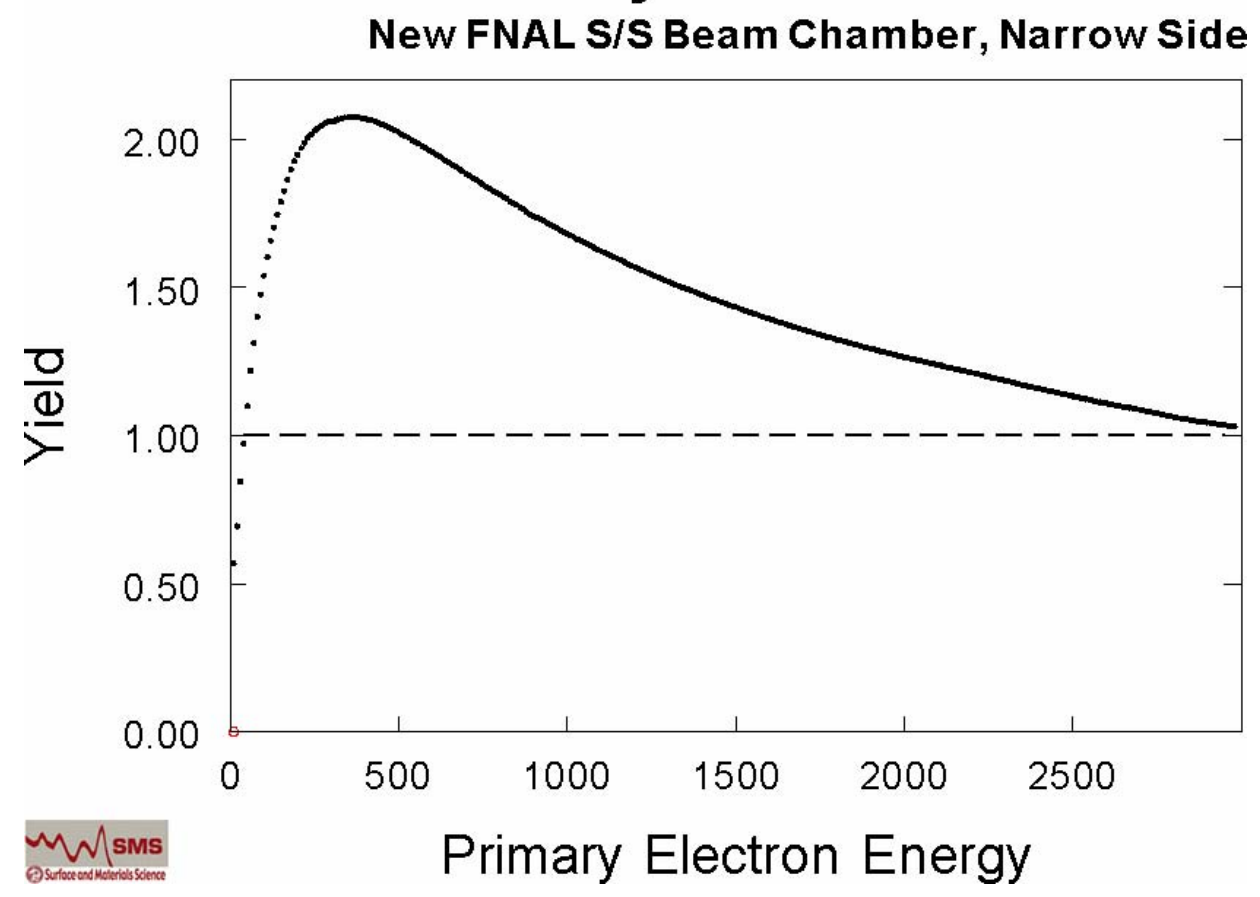

Figure 9. SEY of new S/S chamber material, narrow side. 


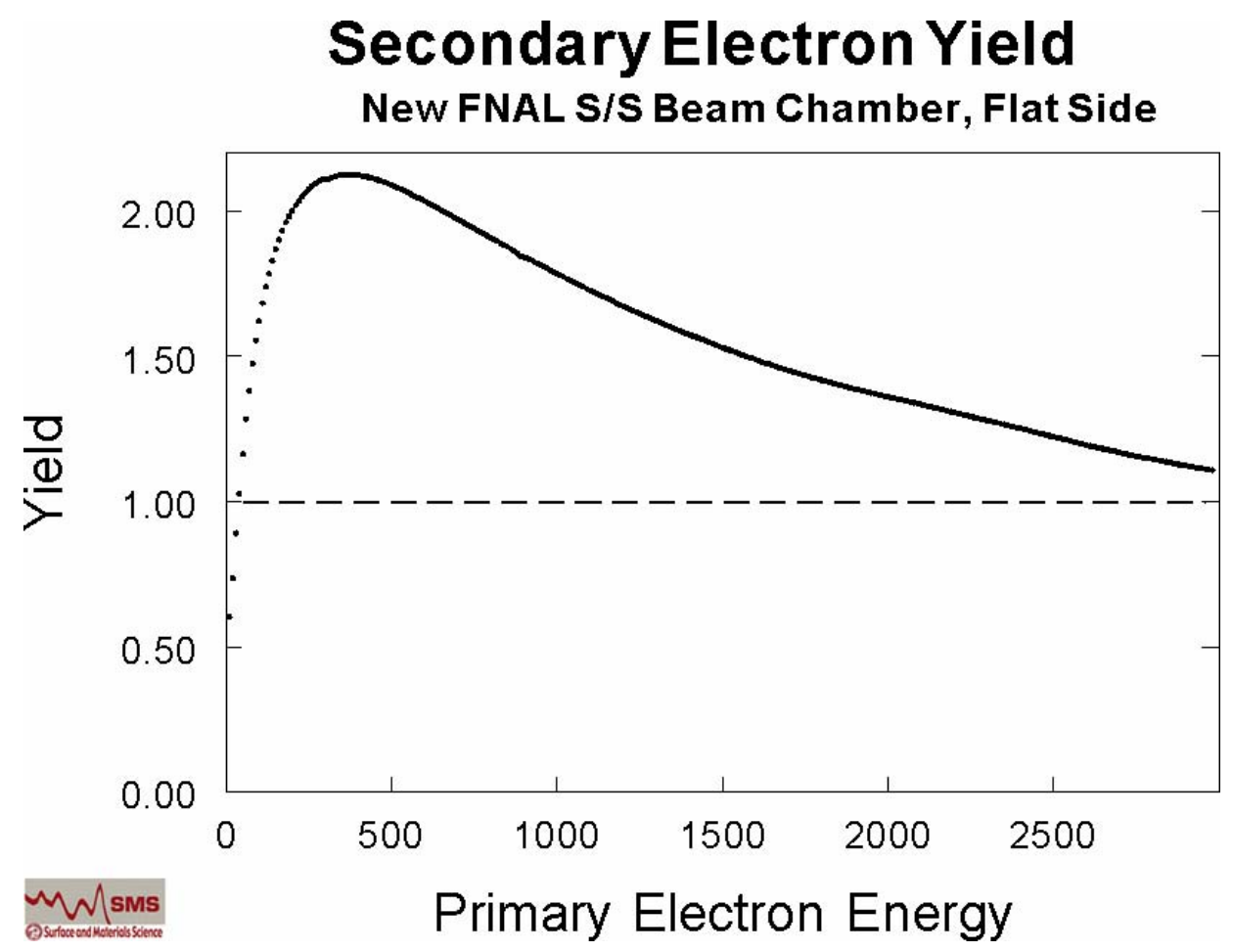

Figure 10. SEY of new S/S chamber material, flat side.

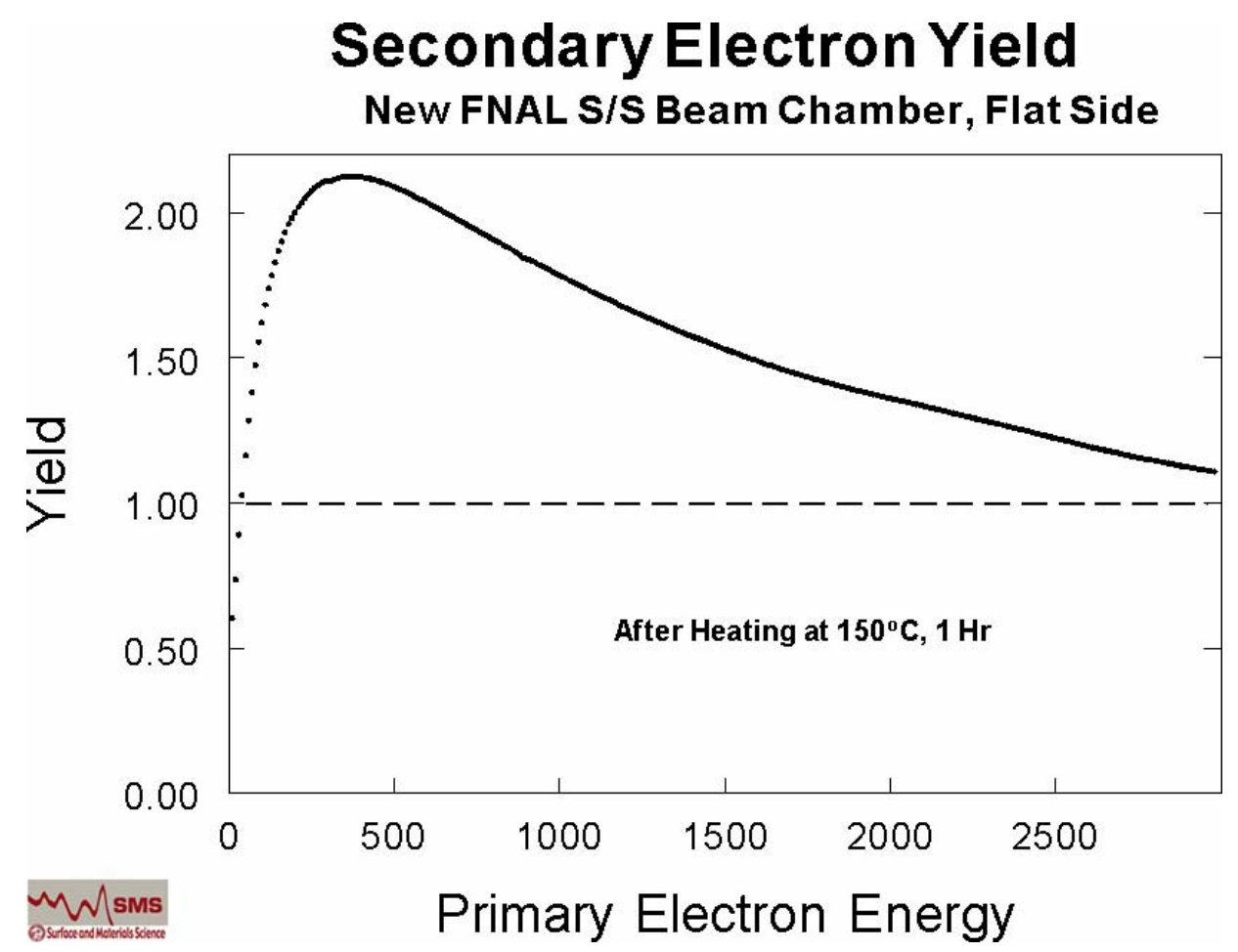

Figure 11. SEY of new S/S chamber material, flat side, after heating to $150^{\circ} \mathrm{C}$ for $1 \mathrm{hr}$ and cooling back to RT. 
Further heating at $150^{\circ} \mathrm{C}$ for 4 hours had no effect on the SEY, namely a peak of 2.12. Following this with heating at $300^{\circ} \mathrm{C}$ for $4 \mathrm{hr}$ did, in fact, drop the yield slightly, to 2.04 (Figure 12).

\section{Secondary Electron Yield}

\section{New FNAL S/S Beam Chamber, Flat Side}

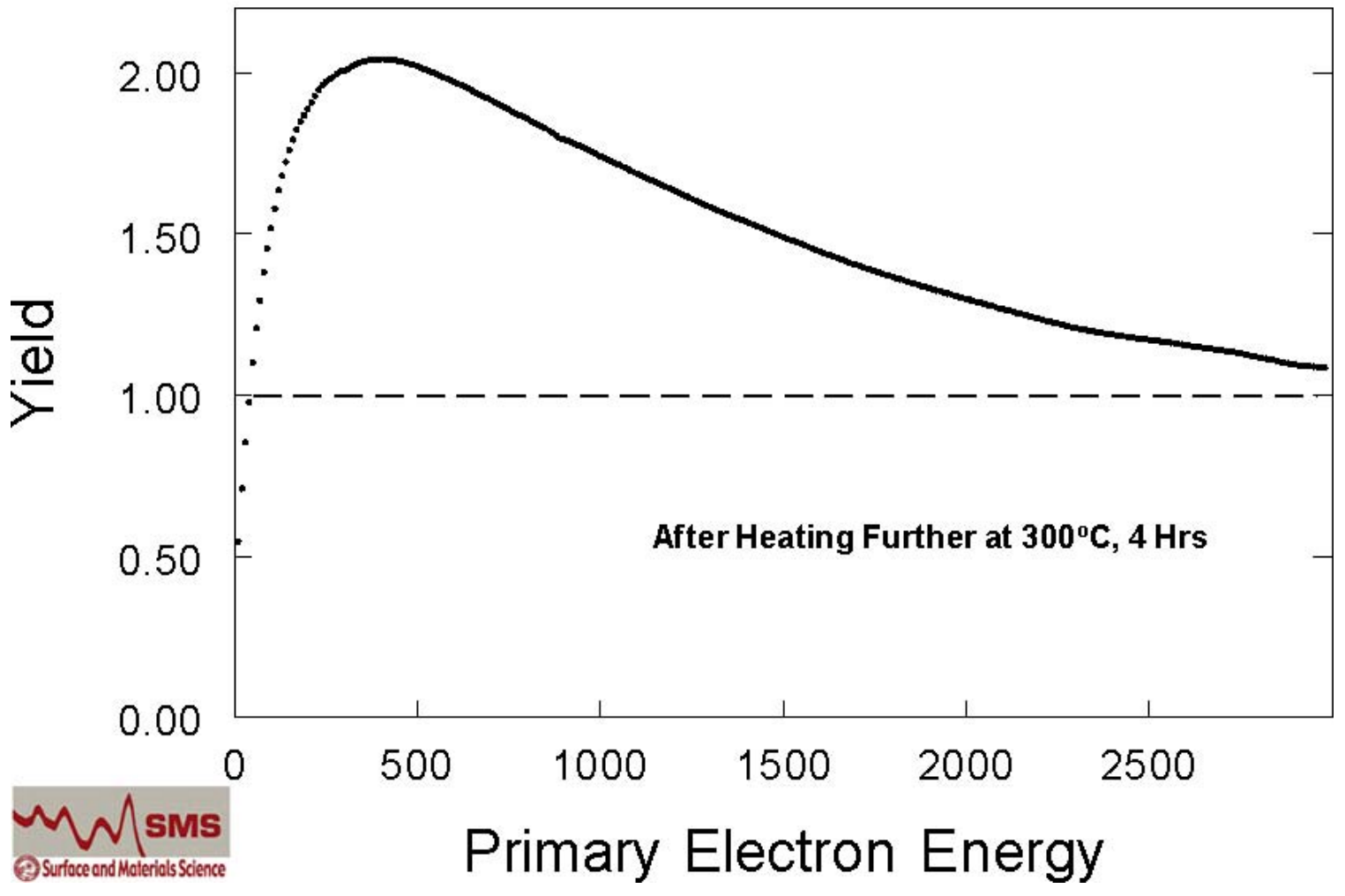

Figure 12. SEY of new S/S chamber material, flat side, after heating to $150^{\circ} \mathrm{C}$ for $4 \mathrm{hr}$ further beyond Fig. 11 , resulting in no change in yield, then heating at $300^{\circ} \mathrm{C}$ for $4 \mathrm{hrs}$ further (yield drops to 2.04).

\section{Conclusions}

- The yield is about right ( 2), compared to previous measurement on technical surfaces of S/S (see O. Grobner, PAC 97, p.3589). "Technical" surfaces are as-received material finish, from the mill or extruder, which is processed only minimally (for example, degreased and lightly-etched). In practical terms, the surface topography is "mill finish" and beam chamber material would be considered technical.

- The XPS is quite clearly of a technical surface with considerable oxide, carbon, and other adventitious matter (sodium, magnesium, sulfur). It seems unaffected by a brief in-situ bakeout. The SEY drops only a little, reflecting that fact. 